\title{
Uusioersily
}

\section{Fabrication of flexible composite drug films via foldable linkages using electrohydrodynamic printing}

Wu, S., Ahmad, Z., Li, J. S., \& Chang, M. W. (2020). Fabrication of flexible composite drug films via foldable linkages using electrohydrodynamic printing. Materials Science and Engineering C, 108, [110393]. https://doi.org/10.1016/j.msec.2019.110393

Link to publication record in Ulster University Research Portal

\section{Published in:}

Materials Science and Engineering $\mathrm{C}$

Publication Status:

Published (in print/issue): 01/03/2020

DOI:

10.1016/j.msec.2019.110393

\section{Document Version}

Author Accepted version

\section{General rights}

Copyright for the publications made accessible via Ulster University's Research Portal is retained by the author(s) and / or other copyright owners and it is a condition of accessing these publications that users recognise and abide by the legal requirements associated with these rights.

\section{Take down policy}

The Research Portal is Ulster University's institutional repository that provides access to Ulster's research outputs. Every effort has been made to ensure that content in the Research Portal does not infringe any person's rights, or applicable UK laws. If you discover content in the Research Portal that you believe breaches copyright or violates any law, please contact pure-support@ulster.ac.uk. 
1 Fabrication of Flexible Composite Drug Films via Foldable Linkages

2 Using Electrohydrodynamic Printing

3

4 Shuting $\mathrm{Wu}^{\mathrm{a}, \mathrm{b}}$, Zeeshan $\mathrm{Ahmad}^{\mathrm{c}}$, Jing-Song Li ${ }^{\mathrm{a}}$, Ming-Wei Chang ${ }^{\mathrm{a}, \mathrm{b}, \mathrm{d}^{*}}$

5

$6{ }^{\text {a }}$ Department of Biomedical Engineering, Key Laboratory of Ministry of Education,

7 Zhejiang University, Hangzhou 310027, P.R. China.

8 b Zhejiang Provincial Key Laboratory of Cardio-Cerebral Vascular Detection

9 Technology and Medicinal Effectiveness Appraisal, Zhejiang University, Hangzhou 10 310027, P.R. China.

$11{ }^{\mathrm{c}}$ Leicester School of Pharmacy, De Montfort University, The Gateway, Leicester, LE1 $129 \mathrm{BH}, \mathrm{UK}$.

$13{ }^{\mathrm{d}}$ Nanotechnology and Integrated Bioengineering Centre, University of Ulster,

14 Jordanstown Campus, Newtownabbey, BT37 0QB, Northern Ireland, UK.

15

$16 *$ Corresponding author: Ming-Wei Chang, Ph.D.,

$17 \quad T e l:+44289536$ 7142, Email: m.chang@ulster.ac.uk

18

19

20

21

22

23 


\section{Abstract}

2 The simple method to manufacture a flexible multi-drug with hydrophilic and

3 hydrophobic molecules-loaded composite membrane via three dimensional (3D)

4 electrohydrodynamic (EHD) printing has been demonstrated in this study. The

5 composite membrane consists of two different drug-loaded sections: cellulose acetate-

6 ibuprofen (CA-IBU) and cellulose acetate-paracetamol (CA-Para), respectively, with

7 an intermediate polycaprolactone (PCL) folding component. The composite

8 membranes can be folded and housed in commercial capsules to aid swallowing. By

9 changing the number of PCL layers in the intermediate layers, it is possible to control

10 and modify the mechanical and unfolding properties of the composite membrane. IBU

11 and Para are loaded into the CA polymeric matrix in their amorphous states, with the

12 matrices exhibiting Higuchi and first order release kinetics, respectively. The

13 combination of IBU and Para can potentially be used as analgesic for patients. Magnetic

14 nanoparticles as a functional material can be incorporated into the PCL matrix for wide

15 targeting and traceable applications. The composite membrane here possesses good 16 biocompatibility and flexibility; enabling extensive application prospects in drug 17 combination therapy and personalized medicine.

Keywords: 3D printing; Folding; Drug delivery; Composite. 


\section{1. Introduction}

2 Dosage forms administered orally (e.g. tablets, capsules, liquids) are the preferred 3 method of giving medication and are known for patient compliance and safety $[1,2]$.

4 Despite this, limitations with respect to controlling drug release and personalizing 5 dosing regimen remain [3]. To circumvent this several strategies have been developed 6 including novel capsule designs (and their manufacturing) which display improved 7 behavior in the gastrointestinal tract $[4,5]$. In addition, multi-functional drug delivery

8 devices or technologies are now coming to the fore to address challenges posed for 9 combination therapy (e.g. for cancer and angiocardiopathy [6, 7]. Recent advances have 10 shown that both hydrophilic and hydrophobic drugs can be incorporated in a single 11 dosage and used in synergy to achieve comprehensive therapeutic effects [8].

12 Three dimensional (3D) electrohydrodynamic (EHD) printing is an ambient 13 environment, non-conventional, one-step process used to prepare 3D microstructures 14 via pre-programmed collector movements [9]. Under optimal applied voltage, the 15 electrified jet undergoes rapid stretching and solidification before reaching the 16 collector. The controlled deposition of fibers is achieved by reducing the distance 17 between nozzle and collector [10]. A variety of materials can be and have been 18 processed to develop pharmaceutical drug carriers via this technique [11]. Compared 19 to other 3D printing techniques (e.g. fused deposition modelling and selective laser 20 sintering), 3D EHD printing provides a processing environment suitable for less 21 thermal stable drugs and the ability to control the process easily and precisely $[12,13]$. 22 Moreover, mesh-structure patterning can be used to control surface hydrophobicity and 23 thus drug release $[14,15]$.

24 Many polymers such as polyvinyl alcohol (PVA), polycaprolactone (PCL) and cellulose acetate (CA) have been used as drug carrier or matrix materials for drug dosage formulations [16-18]. PCL is a biocompatible polymer with good mechanical properties, which has been applied for various applications requiring strength, such as surgical sutures, wound dressings and filtration [19-21]. Cellulose acetate (CA) is generally prepared through an esterification reaction of cellulose with acetic anhydrides [22]. Due to the biodegradability, hydrophillic nature and excellent stability of CA, it

31 has been widely used for many bio-interfacing applications [23-25], as drug encapsulating matrices, and for drug delivery applications [26]. 
1 In recent years, research has been directed towards improving comfort for patients with

2 respect to pain when administrating treatment. Based on this, drug combination

3 therapies have been put forward with the superiority of better analgesic effect when

4 compared to monotherapy [27], whilst improving patient compliance and convenience

5 [28]. Ibuprofen (IBU) is a widely used non-steroidal anti-inflammatory drug (NSAID)

6 with very little side effects, which is used to treat pain and inflammation [29].

7 Paracetamol (Para) is prescribed as an analgesic and antipyretic with good tolerance

8 and safety [30]. Both IBU and Para are used for pain relief after surgery [31]. It has

9 been proved that the combination of IBU and Para can provide a significantly more

10 effective treatment of acute pain than monotherapies [32].

11 In this study, we demonstrate the engineering of a flexible multi-drug dosage membrane

12 hosting both hydrophilic and hydrophobic molecules via three dimensional (3D)

13 electrohydrodynamic (EHD) printing. The flexible composite film comprises foldable

14 linkages and the unfolding process enables increased surface area for expedited drug

15 release and increasing retention time which is ideal to reduce dosing. Moreover, loading

16 into different compartments of the composite membrane is a proof-of-concept for

17 combinatorial therapy which is shown via precision 3D printing. The flexible composite

18 membrane with one central component can be folded and enclosed into capsules for

19 oral administration. Composite membranes with different thickness have been

20 fabricated by altering the number of layers of the central components $(5,10$ and 20

21 layers, respectively) to investigate the impacts of the central component layer numbers

22 on the mechanical property and unfolding property of the composite membranes and to

23 find the relatively best parameter. Also, the unfolding process is crucial in terms of

24 expansion potential which is useful for the current application as it can increase the

25 surface area of printed membranes and also prolong retention time in the

26 gastrointestinal tract. IBU and Para were loaded into different regions of the composite

27 membrane and were selected as model drugs to show proof-of-concept for

28 combinatorial therapy and to enable multiple drug release behavior for personalized

29 medicine. Magnetic nanoparticles were added into the central PCL component for

30 potential targeting applications.

\section{Materials and Methods}


2 Cellulose acetate $\left(\mathrm{CA}, \mathrm{M}_{\mathrm{w}}=30000 \mathrm{~g} / \mathrm{mol}\right)$, polycaprolactone (PCL, $\left.\mathrm{M}_{\mathrm{w}}=80000 \mathrm{~g} / \mathrm{mol}\right)$

3 and ibuprofen (IBU, $\geq 98 \%$ ) were all obtained from Sigma-Aldrich, USA. Paracetamol

4 (Para, $\geq 99 \%$ ) were purchased from Aladdin, China. Acetone, N, N-

5 Dimethylformamide (DMF), acetic acid and phosphate buffer saline (PBS, pH=7.4)

6 were all obtained from Sinopharm Chemical Reagent, China. Magnetic nanoparticles

$7 \quad\left(\mathrm{Fe}_{3} \mathrm{O}_{4} \mathrm{NPs}\right)$ were supplied by HWRK Chem, China. Deionized water (DI water) was

8 prepared in-house (Millipore Milli-Q Reference ultra-pure water purifier, USA).

9 Minimum Eagle's medium (MEM, Gibco) and fetal bovine serum (FBS) were obtained

10 from Invitrogen, USA. All chemicals used were of analytical grade.

\subsection{Preparation of $3 D$ EHD printing solutions}

Acetone and DMF (acetone:DMF=1:1, v/v) were used to dissolve CA at the concentration of $22 \%(\mathrm{w} / \mathrm{w})$ by mechanical stirring (VELP ARE heating magnetic stirrer, Italy) for 5 hours. IBU $(5 \% \mathrm{w} / \mathrm{w}$ of CA) and Para $(4 \% \mathrm{w} / \mathrm{w}$ of CA) were then added to the CA solution, respectively, and dissolved by mechanical stirring for 2 hours to obtain homogenous IBU-loaded CA solution and Para-loaded CA solution. The drug concentration of IBU and Para were altered to demonstrate practical feasibility of personalization and drug loading capabilities for co-therapy.

PCL was dissolved in acetic acid at a concentration of $24 \% \mathrm{w} / \mathrm{w}$ under mechanical stirring (VELP ARE heating magnetic stirrer, Italy) for 6 hours at room temperature. $\mathrm{Fe}_{3} \mathrm{O}_{4} \mathrm{NPs}$ were added to the PCL solution at a concentration of $0.5 \% \mathrm{w} / \mathrm{w}$, which was dispersed through bath sonication for 2 hours to yield a homogeneous suspension.

\subsection{Preparation of composite membrane}

The 3D EHD printing set-up was shown in Fig. 1, including a stainless steel nozzle (outer diameter $=0.9 \mathrm{~mm}$, inner diameters $=0.7 \mathrm{~mm})$, a syringe pump $(\mathrm{KD}$ Scientific KDS100, USA), a high voltage power supply (Glassman high voltage Inc. series FC, USA) and a controllable X-Y $-Z$ movement stage. Firstly, the $5 \mathrm{ml}$ syringe was loaded with drug solutions and infused through the printing nozzle at a flow rate of $0.3 \mathrm{ml} / \mathrm{h}$. The path of movement stage was pre-designed and programmed (Adtech, China) in a grid pattern. Under the optimum preparation parameters (applied voltage of $2 \mathrm{kV}$, 
nozzle-to-collector distance of $2 \mathrm{~mm}$ and movement stage speed of $100 \mathrm{~mm} / \mathrm{s}$ ), well

2 aligned drug-loaded films with grid shapes were fabricated $(6.5 \times 13 \mathrm{~mm})$ within $5 \mathrm{~min}$.

3 The layer number of the drug-loaded films were set as 10 layers.

4 The CA-IBU film and CA-Para film were then linked by the PCL fibrous central 5 component to obtain a flexible, composite membrane. The distance between CA-IBU and CA-Para films was $2 \mathrm{~mm}$. The printing parameters of the central component was optimized to achieve a stable printing Taylor cone. The applied voltage and nozzle-tocollector distance were set to $2 \mathrm{kV}$ and $3 \mathrm{~mm}$, respectively. The flow rate of PCL solution was $0.2 \mathrm{ml} / \mathrm{h}$ and the speed of the movement stage was $40 \mathrm{~mm} / \mathrm{s}$. The layer number of the central component was set to 5, 10 and 20 layers, respectively (denoted as $\mathrm{P} 5, \mathrm{P} 10$ and $\mathrm{P} 20)$.

\subsection{Mechanical characterization}

The mechanical characterization of tension was investigated using a universal material testing machine (Zwick/Roell Z020, Zwick, Germany). The sizes of P5, P10 and P20 were all $13.5 \times 15 \mathrm{~mm}$ and the thickness of the central components were approximately $40 \mu \mathrm{m}, 70 \mu \mathrm{m}$ and $140 \mu \mathrm{m}$, respectively. Each specimen was fixed by the grips and then tensioned at a rate of $10 \mathrm{~mm} / \mathrm{min}$ until the composite membranes fractured. Each sample was performed in triplicate.

\subsection{Unfolding property test}

The unfolding property of the composite membranes was tested in vitro. Each composite membrane was folded and encased in empty capsules (size 0 ). The composite membrane-loaded capsules were then placed into a $100 \mathrm{ml}$ beaker, containing $60 \mathrm{ml}$ PBS $\left(37^{\circ} \mathrm{C}\right)$. After being left to stand for 15 minutes, the unfolding angles of composite membranes with different folding-part layers were measured using ImageJ software (version 1.48, National Institute of Health, USA). The same test but placed in a HZ$8801 \mathrm{~K}$ thermostatic oscillator (Taicang Science and Education Factory, China) was also performed and analyzed.

\subsection{Fourier transform infrared (FTIR) spectroscopy}

The spectra of CA, Para, PCL and the composite membrane were analyzed by Fourier transform infrared spectroscopy (FTIR, IR Affinity 1, Shimadzu, Japan). For each test 
1 disk, $3 \mathrm{mg}$ sample was mixed with $300 \mathrm{mg} \mathrm{KBr}$ powders and then pressed into a

2 transparent disk. The disks were then used for FTIR analysis between 400 and 4800

$3 \mathrm{~cm}^{-1}$ and the resolution was set as $4 \mathrm{~cm}^{-1}$.

4 2.7. Differential scanning calorimetry (DSC) and X-ray diffraction (XRD)

5 Thermal analysis was performed using differential scanning calorimetry (DSC) (PE

6 DSC 7, Perkin-Elmer, USA). Samples ( $3 \mathrm{mg}$ ) were heated over a temperature range

7 of 30 to $260^{\circ} \mathrm{C}$, at a heating rate of $10^{\circ} \mathrm{C} / \mathrm{min}$ in the $\mathrm{N}_{2}$ environment.

8 XRD analysis of each sample was performed by X-ray crystal diffractometer (Gemini

9 A Ohra, Oxford, UK). The printed membrane was cut into pieces and then sent to XRD

10 test center for analysis. The scan range of 2 theta was between $5^{\circ}$ and $60^{\circ}$ at a step

11 size of $0.02^{\circ}$. The voltage and intensity were $40 \mathrm{kV}$ and $40 \mathrm{~mA}$.

12

13

14

15

16

17

18

19

20

21

22

23

24 Drug release $(\%)=\frac{C_{t}}{C_{M}} \times 100 \%$

Where $C_{t}$ is the drug release in the solution at time $t$ and $C_{M}$ is the total drug release in the solution.

27 The drug encapsulation efficiency (EE) can be calculated as Equation 2 [33].

28 EE $(\%)=\frac{\text { Amount of drug encapsulated in membranes }}{\text { Theoretical amount of drug }} \times 100 \%$ 
1 The drug loading capacity (LC) can be obtained using Equation 3 [34].

2 LC $(\%)=\frac{\text { Amount of drug encapsulated in membranes }}{\text { weight of the membrane }} \times 100 \%$

3

4

5

\subsection{Kinetics of drug release}

The drug release mechanisms of IBU and Para from composite membranes were analyzed by fitting release data to zero-order, first-order, Higuchi and KorsmayerPeppas mathematic models $[14,35]$. The best fit model for drug release can be determined by comparing the correlation coefficient $\left(\mathrm{R}^{2}\right)$.

\subsection{Scanning electron microscopy (SEM) characterization}

Scanning electron microscopy (SEM, Eindhoven, Netherlands) was used to investigate the morphology of the composite membranes. Each Sample was sputter-coated with gold for $90 \mathrm{~s}$ before the observation. The accelerating voltage was set as $10 \mathrm{kV}$. Image J software (National Institute of Health, USA) was used to determine the diameters of the printed fibers. The diameter distribution diagrams were obtained by Origin software (version 8.0, Originlab, USA).

\subsection{Magnetic test}

The magnetic property of the printed composite membrane was investigated using a vibration sample magnetometer (VSM Mini-CFM measurement system, Cryogenic Ltd., UK) at $300 \mathrm{~K}$. Composite membrane with a known weight was placed in the magnetometer and measured in a range of -10000 Oe to 10000 Oe.

\subsection{Cell culture}

In order to analyze the biocompatibility of the printed composite membrane, L929 mouse fibroblast cells were cultured on the composite membrane with MEM medium containing $1 \%$ antibiotic-antimycotic and $10 \% \mathrm{FBS}$ in a $6 \mathrm{~cm}$ diameter culture dish at $37{ }^{\circ} \mathrm{C}$, under $5 \% \mathrm{CO}_{2}$ environment.

After 3 days incubation, cells were fixed with 4 (v/v) \% formalin for $30 \mathrm{~min}$ and then permeabilized by $0.1 \%$ Triton X-100 for $5 \mathrm{~min}$. After being washed three times with PBS, Alexar Fluor 546 phalloidin (1:200 v/v of phalloidin:PBS, Invitrogen, USA) were used to stain the cell cytoskeleton for 20 min followed by triple PBS rinses. 4', 6'- 
1 diamidino-2-phenylindole hydrochloride (DAPI, 1:5000 v/v of DAPI:PBS, Invitrogen,

2 USA) was then used to stain the cell nuclei for $5 \mathrm{~min}$ followed by PBS rinses two times.

3 The cell distribution on the composite membrane was observed by a fluorescent

4 microscope (Nikon Ti-S, Japan).

\section{Results and Discussion}

\subsection{Preparation and characterization of composite membranes}

8 The printed composite membranes and their capsules are shown in Fig. 2. The

9 composite membranes demonstrated grid structure as a result of the pre-determined 10 patterns. The central component (PCL) provides flexability; allowing the composite 11 membrane to fold and thus allowing the composite membranes to be enclosed in size 0 capsules for oral administration. To investigate the effect of the central component layer numbers on mechanical properties and unfolding properties, composite membranes with 5 layers, 10 layers and 20 layers of intermediate PCL component, respectively, were printed and denoted as P5, P10 and P20 accordingly, and the mean weights were measured to be $3.2 \pm 0.1,3.6 \pm 0.2$ and $4.2 \pm 0.1 \mathrm{mg}$, respectively.

The tensile stress-strain curves of the composite membranes with different folding layers (P5, P10 and P20) are shown in Fig. 3a. It can be seen that the stress-strain curve of P5 was typical for fiber tension exhibiting three characteristic stages including a linear elastic section (region A), a progressive deformation section (region B) and a failure section (region C) [36]. It has been proven that thickness of the fibrous mats affects the its strength [37]. The tensile stress-strain curve of P10 was similar to that of P5 with three characteristic stages. However, here there was a much larger maximum stress due to the increased number of layers of PCL in P10.

The stress-strain curve of P20 showed very different results. An arrow-like pattern with a much smaller elongation was found. During the tension process of P20, the fiber breakage happened on the joint between the drug-loaded sectors and the folding sector, as the insert in Fig. 3a shows.

29 As shown in Fig. 3b, as the layer number of the central component increased, the 
1 maximum stress of the composite membrane increased from $0.47 \pm 0.01 \mathrm{Mpa}$ to $1.52 \pm$

$20.20 \mathrm{MPa}$, while the maximum strain of the composite membrane decreased from 182

$3 \pm 35 \%$ to $15 \pm 3 \%$. The elastic moduli of P5, P10 and P20 are calculated to be 0.07 ,

40.36 and $0.72 \mathrm{Mpa}$, respectively. It is evident that the number of PCL layers plays an

5 important role in the mechanical properties of the composite membranes. The good

6 mechanical property is beneficial for the unfolding property and resisting destruction

7 ability of composite membranes.

8 To investigate the impact of the central component layer numbers on the unfolding

9 properties, unfolding tests of the composite membranes (P5, P10 and P20) were 10 performed with the unfolding angle data being depicted as shown in Fig. 4. After 15 11 minutes' standing, the capsule shells dissolved, and the folded composite membranes 12 re-spread out as the inserts of Fig. 4a shows. The unfolding angles of P5, P10 and P20 13 were calculated to be $44.2 \pm 5.8^{\circ}, 116.0 \pm 5.4^{\circ}$ and $145.2 \pm 2.2^{\circ}$, respectively. This 14 indicates that the unfolding properties of the composite membranes improved with the 15 increase of the central component layer numbers. The results of the similar unfolding 16 test placed in a HZ-8801K thermostatic oscillator for 15 minutes, showed the same 17 varying tendency that the unfolding angles changed from $92.2 \pm 7.4^{\circ}$ to $148.7 \pm 18.3^{\circ}$, 18 as the central component layer number increased from 5 layers to 10 layers. In addition, 19 the unfolding angles of composite membranes with oscillation were larger than those 20 without oscillation, especially P5 which was due to the smaller residual strain and better 21 flexibility. This indicates that oscillation can facilitate the unfolding process of the 22 composite membranes. Taking into consideration of the mechanical properties and 23 unfolding properties as well as the preparation process, P10 was selected as a sample 24 for subsequent studies.

25 The SEM images of three all 3 sectors in the composite membrane are shown in Fig. 5. 26 Fig. 5a shows the micrograph of the central component with a grid structure. The 27 diameter distribution of the PCL fibers is between $4 \mu \mathrm{m}$ to $19 \mu \mathrm{m}$, and the mean 28 diameter of PCL fibers is $10.5 \pm 3.2 \mu \mathrm{m}$. Fig. 5a' depicts a detailed image of a PCL 29 fiber, showing the precise stack of the printed PCL fibers with 10 layers. The SEM 30 images of the CA-Para sector and CA-IBU sector of the composite membrane are 31 shown in Figs. 5b and 5c, respectively. It can be seen that both CA-Para matrix and 32 CA-IBU matrix were designed and printed in a grid structure with the grid cell size of 
$1500 \times 500 \mu \mathrm{m}^{2}$. The mean diameters of CA-Para fibers and CA-IBU fibers are $15.7 \pm$

$2 \quad 3.6 \mu \mathrm{m}$ and $18.4 \pm 4.8 \mu \mathrm{m}$, respectively. As shown in Figs. 5b' and 5c', both printed

3 fibers were well aligned and stacked layer by layer precisely with uniform

4 morphologies. This demonstrates the precision control via 3D EHD printing to

5 manufacture patterned composite membranes.

\subsection{FTIR analysis of the composite membrane}

7 To confirm the stability of the compositions and the possible interactions between the

8 materials of the composite membrane, FTIR analysis was performed (Fig. 6). For pure

9 PCL, the characteristic absorption peaks at $2947 \mathrm{~cm}^{-1}$ and $1730 \mathrm{~cm}^{-1}$ are attributed to

10 the asymmetric stretching of $\mathrm{CH}_{2}$ and carbonyl stretching, respectively [38]. The

11 absorption peak at $1170 \mathrm{~cm}^{-1}$ is related to the stretching of $-\mathrm{C}-\mathrm{O}$ [39]. These peaks can

12 be identified in the composite membrane spectrum, confirming the presence of PCL in

13 the composite membrane.

14 For pure CA, the characteristic bands at $3495 \mathrm{~cm}^{-1}, 1373 \mathrm{~cm}^{-1}$ and $1045 \mathrm{~cm}^{-1}$ are due to 15 the $-\mathrm{O}-\mathrm{H}$ group stretching, $-\mathrm{C}-\mathrm{CH}_{3}$ group stretching and $-\mathrm{C}-\mathrm{O}$ - bond stretching, 16 respectively [40]. For pure IBU, the intense peak at $1720 \mathrm{~cm}^{-1}$ is assigned to the 17 carbonyl $(\mathrm{C}=\mathrm{O})$ stretching [41], which is overlapping with PCL peak and can be seen 18 in the composite membrane spectrum. The absorption bands at $1230 \mathrm{~cm}^{-1}$ and $937 \mathrm{~cm}^{-}$

191 are due to the stretching of $\mathrm{C}-\mathrm{C}$ bond and rocking vibration of $\mathrm{CH}_{3}$ [42], respectively, 20 which, although weak, can be found in the spectrum for composite membrane. For pure 21 Para, the characteristic absorption peaks located at $3319 \mathrm{~cm}^{-1}$ and $1554 \mathrm{~cm}^{-1}$ are 22 corresponding to - $\mathrm{O}-\mathrm{H}$ group stretching and $\mathrm{N}-\mathrm{H}$ group stretching, respectively [27]. 23 All these characteristic peaks appear in the composite membrane spectrum, suggesting 24 the presence of the drugs in the printed composite membrane. Hence, no additional 25 peaks or peak changes were observed in the FTIR spectrum, indicating no physical 26 incompatibilities between the components.

\subsection{DSC and XRD analysis of the composite membrane}

28 The DSC curves of pure PCL, CA, Para, IBU and the printed composite membrane are 29 shown in Fig. 7a. An endothermal peak is present at $56.7^{\circ} \mathrm{C}$ for pure PCL, indicating 30 the melting point $\left(\mathrm{T}_{\mathrm{m}}\right)$ of PCL [42]. For pure CA, the first endothermal peak at $67.5^{\circ} \mathrm{C}$ 31 and the second peak observed at $230.9^{\circ} \mathrm{C}$ correspond to the glass transition temperature 
1 ( $\mathrm{T}_{\mathrm{g}}$ ) of CA, and the melting peak of CA is very close to the its $\mathrm{T}_{\mathrm{g}}$ peak around $237^{\circ} \mathrm{C}$

2 [43]. The DSC curve of pure Para shows a well-defined melting peak at $169.2{ }^{\circ} \mathrm{C}$ [3].

3 The sharp endothermic peak located at $77.2{ }^{\circ} \mathrm{C}$ corresponds to the melting temperature

4 of pure IBU [44]. For the composite membrane, there are no significant changes in the

5 melting peaks of the polymer PCL and CA, but a slight shift can be identified from 56.7

$6{ }^{\circ} \mathrm{C}$ to $51.1^{\circ} \mathrm{C}$ for PCL and from $230.9^{\circ} \mathrm{C}$ to $222.8^{\circ} \mathrm{C}$ for $\mathrm{CA}$. Besides, the endothermal

7 peaks of Para and IBU cannot be seen in the DSC curve of the composite membrane,

8 indicating the amorphous state of both drugs in the printed composite membrane.

9 The XRD results further confirmed that both drugs were incorporated in the composite 10 membrane in their amorphous forms. As shown in Fig. 7b, the sharp crystalline 11 diffraction peaks of pure Para and IBU were not detectable in the XRD spectrum of the 12 composite membrane because of their dispersion within the matrix material[18]. 13 Although the drug loading was low, it was above the detection limits and can be 14 successfully detected $[12,45,46]$.

\subsection{In vitro drug release test}

The release studies were performed in an acidic medium (gastric $\mathrm{pH}$ ) for the first two hours then at intestinal pH (PBS) for 6 hours. As seen in Fig. 8, almost 100\% of Para was released in the first 2 hours in the gastric medium. In contrast to Para release, IBU release was slower: almost 35\% IBU was released during the gastric phase with subsequent sustained release in the intestinal phase. These different release behaviors may be due to the fact that Para is hydrophilic, and IBU is hydrophobic and weak acidic with poor solubility in the acidic media [47, 48]. Fig. 9 shows the SEM images of the three parts of the composite membranes after $8 \mathrm{~h}$ drug release test. It can be seen that CA-Para, central and CA-IBU components of composite membrane maintain their grid structures and show no obvious eroding or disintegrating. The magnified images in Figs. 9a', 9b' and 9c' show that the surface morphologies of CA-Para, CA-IBU and central components were all uniform after drug release due to high polymer stability.

The release mechanisms of Para and IBU from the composite membrane was investigated by fitting the release data to zero-order model, first-order model, Higuchi model and Korsmayer-Peppas mathematic model, as shown in Tab. 1. For Para release, it is best fitted by first order model with the highest correlation coefficient $R^{2}=0.9759$ [49]. IBU was best fitted by Higuchi kinetics with $\mathrm{R}^{2}$ value of 0.9928 , indicating the 
1 Fickian diffusion mechanism of IBU, which is further confirmed by Korsmeyer-Peppas

2 modelling with $n$ value of 0.5 [50].

3 The EE of IBU and Para were calculated to be $85.7 \pm 7.2 \%$ and $87.9 \pm 1.8 \%$,

4 respectively. Maximum EE is not obtained because drug partially diffuses from the

5 semi-liquid polymer on the collector due to evaporation [51]. Moreover, the LC of IBU

6 and Para were calculated to be $2.5 \pm 0.3 \%$ and $1.3 \pm 0.2 \%$, respectively. The results

7 indicate the feasibility of encapsulating drugs via 3D EHD printing.

$8 \quad 3.5$. Magnetic property

9 Magnetic nanoparticles $\left(\mathrm{Fe}_{3} \mathrm{O}_{4} \mathrm{NPs}\right)$ could be added in the central component, by 10 simply adding them to the printing solution, to further functionalize the composite 11 membranes with magnetic properties. Vibration sample magnetometer (VSM) analysis 12 was performed to quantify the magnetic properties of the composite membrane at a 13 constant temperature $(300 \mathrm{~K})$. The hysteresis loop of the printed composite membrane 14 in the field range between -10000 Oe and 10000 Oe is shown in Fig. 10a. The hysteresis 15 loop shows a S-shaped curve with no remanence and coercivity, and the curve goes 16 though the zero point. The saturation magnetization value of the composite membrane 17 is $0.16 \mathrm{emu} / \mathrm{g}$. Therefore, the results manifest the superparamagnetic nature of the 18 printed composite membrane [52]. For better visualization, the magnetic property of 19 the composite membrane was evaluated by a permanent magnet as shown in Fig. 10b. 20 The composite membranes (in distilled water) were drawn to the attracting side by a 21 magnet and was recovered after removal of the magnet. The magnetic composite 22 membranes may have many potential applications such as (but not limited to) magnetic 23 targeting, visualization in MRI and magnetic heating [53, 54].

\subsection{Biocompatibility analysis}

PCL and CA are FDA approved materials which are widely used in the pharmaceutical industry $[55,56]$. However, it is still necessary to investigate the biocompatibility of the composite membranes, due to the potential toxicity of actives and solvents used during the preparation procedures. Herein, L929 cells were cultured on the composite membrane for 3 days. The morphologies of L929 cells were observed through fluorescence microscope as shown in Fig. 11. Figs. 11a, 11b and 11c display the merged fluorescent images of cells growing on the CA-IBU part, CA-Para part and the central 
1 component, respectively. Figs. 11a', 11b' and 11c' are the magnified images of Figs.

$211 \mathrm{a}, 11 \mathrm{~b}$ and $11 \mathrm{c}$, respectively, showing the detailed cell morphology on the composite

3 membrane. From the inserts of bright field images, it can be seen that cells grew well

4 with the composite membranes, highlighting the good biocompatibility of the

5 composite membranes.

\section{4. Conclusion}

8 In summary, multi-drug-loaded composite membranes consisting of the drug-loaded 9 parts and intermediate folding section were prepared via 3D EHD printing successfully. 10 The composite membrane found to deliver two drugs with well-defined drug release 11 mechanisms. IBU and Para were respectively loaded in two different CA films in their 12 amorphous forms, and linked by the PCL folding layer for the treatmemt of fever or 13 pain alleviation. The mechanical property and unfolding property of the composite 14 membranes were controllable by regulating the layer number of the folding layer. The 15 composite membranes were able to be folded and capsulated into capsules for ease of 16 swallowing, and re-spread out during drug release process. The magnetic property of 17 the composite membrane can be obtained by adding magnetic NPs into the middle PCL 18 layer for targeting applications. The good biocompatibility of the composite membrane was proved via L929 cell culture experiments. These composite membranes were controllable and flexible, and possess potential applications in drug combination therapy and personalized medicine.

\section{Acknowledgements}

24 This research was financially supported by the National Nature Science Foundation of 25 China (No. 81771960), the Fundamental Research Funds for the Central Universities 26 (2017QNA5017) and Key Technologies R\&D Program of Zhejiang Province 27 (2015C02035). 
[1] L. Susanne, A.N. Huddleston, Expert Rev. Anticancer Ther., 15 (2015) 1-12.

3 [2] G.D. Anderson, R.P. Saneto, Adv. Drug Del. Rev., 64 (2012) 911-918.

[3] A. Goyanes, M.P. Robles, A. Buanz, A.W. Basit, S. Gaisford, Int. J. Pharm., 494 (2015) 657-663.

[4] A.M. Bellinger, M. Jafari, T.M. Grant, S. Zhang, H.C. Slater, E.A. Wenger, S. Mo, Y.L. Lee, H. Mazdiyasni, L. Kogan, Sci. Transl. Med., 8 (2011) 365ra157.

[5] J. Liu, Y. Pang, S. Zhang, C. Cleveland, X. Yin, L. Booth, J. Lin, Y.A. Lucy Lee, H. Mazdiyasni, S. Saxton, A.R. Kirtane, T.V. Erlach, J. Rogner, R. Langer, G. Traverso, Nat. Commun., 8 (2017) 124.

[6] Y. Ning, M. Wenzhe, P. Jianfeng, O. Qi, T. Chao, L. Luhua, PLoS One, 9 (2014) 93960.

[7] G.L. Chen, L. Zhang, P. Chen, X.P. Xu, Chin. J. New Drugs, 25 (2016) 2205-2210. [8] S.A. Khaled, J.C. Burley, M.R. Alexander, J. Yang, C.J. Roberts, J. Control. Release., 217 (2015) 308-314.

[9] Z.-C. Yao, J.-C. Wang, Z. Ahmad, Mat. Sci. Eng. C-Mater., 97 (2019) 776-783. [10] J.C. Wang, H. Zheng, M.W. Chang, Z. Ahmad, J.S. Li, Sci. Rep., 7 (2017) 43924. [11] G. Jonathan, A. Karim, Int. J. Pharm., 499 (2016) 376-394.

[12] A. Goyanes, A.B. Buanz, G.B. Hatton, S. Gaisford, A.W. Basit, Eur. J. Pharm. Biopharm., 89 (2015) 157-162.

[13] F. Fina, C.M. Madla, A. Goyanes, J. Zhang, S. Gaisford, A.W. Basit, Int. J. Pharm., 541 (2018).

[14] S. Wu, Z. Ahmad, J.S. Li, M.W. Chang, Mater. Lett., 232 (2018) 134-137. [15] J.-C. Wang, M.-W. Chang, Z. Ahmad, J.-S. Li, Journal of Drug Delivery Science and Technology, 35 (2016) 114-123.

[16] J. Skowyra, K. Pietrzak, M.A. Alhnan, Eur. J. Pharm. Sci., 68 (2015) 11-17. [17] A.R. Kirtane, O. Abouzid, D. Minahan, T. Bensel, A.L. Hill, C. Selinger, A. Bershteyn, M. Craig, S.S. Mo, H. Mazdiyasni, C. Cleveland, J. Rogner, Y.L. Lee, L. Booth, F. Javid, S.J. Wu, T. Grant, A.M. Bellinger, B. Nikolic, A. Hayward, L. Wood, P.A. Eckhoff, M.A. Nowak, R. Langer, G. Traverso, Nat. Commun., 9 (2018) 2. [18] S. Wu, J.-S. Li, J. Mai, M.-W. Chang, Acs. Appl. Mater. Interfaces, 10 (2018) 24876-24885.

[19] H. Yoshimoto, ., Y.M. Shin, H. Terai, ., J.P. Vacanti, Biomaterials, 24 (2003) 2077-2082.

[20] S. Wu, B. Wang, Z. Ahmad, J. Huang, M.W. Chang, J.S. Li, Mater. Lett., 204 (2017) 73-76.

[21] M.A. Woodruff, D.W. Hutmacher, Prog. Polym. Sci., 35 (2010) 1217-1256.

[22] H. Kono, C. Oka, R. Kishimoto, S. Fujita, Carbohyd. Polym., 170 (2017) 23-32.

[23] A. Rajeswari, S. Vismaiya, A. Pius, Chem. Eng. J., 313 (2017) 928-937.

[24] L. Wei, T. Li, G. Li, L. An, L. Fan, Z. Zhang, Carbohyd. Polym., 168 (2017) 153162.

[25] L. Wu, X. Yin, Z. Guo, Y. Tong, J. Feng, P. York, T. Xiao, M. Chen, J. Gu, J. Zhang, Eur. J. Pharm. Sci., 84 (2016) 132-138.

[26] R. Konwarh, N. Karak, M. Misra, Biotechnol. Adv., 31 (2013) 421-437.

[27] A.P. Chiriac, A. Diaconu, L.E. Nita, N. Tudorachi, L. Mititelutartau, A. Creteanu, O. Dragostin, D. Rusu, G. Popa, Expert. Opin. Drug. Del., 14 (2017) 1.

[28] A. Goyanes, J. Wang, A. Buanz, R. Martínezpacheco, R. Telford, S. Gaisford, A.W. Basit, Mol. Pharm., 12 (2015) 4077-4084.

[29] K.J. Hartlieb, D.P. Ferris, J.M. Holcroft, I. Kandela, C.L. Stern, M.S. Nassar, Y.Y. Botros, J.F. Stoddart, Mol. Pharm., 14 (2017) 1831-1839. 
[30] J.C. Mccrae, E.E. Morrison, I.M. Macintyre, J.W. Dear, D.J. Webb, Br. J. Clin. Pharmacol., (2018).

[31] G.E. Kayhana, M. Sanli, U. Ozgul, R. Kirteke, S. Yologlu, J. Clin. Anesth., 50 (2018) 5-11.

[32] S. Daniels, H. Atkinson, I. Stanescu, C. Frampton, Clin. Ther., 40 (2018) 17651776.

[33] S. Wu, B. Wang, Z. Ahmad, J. Huang, M.W. Chang, J.S. Li, Materials Letters, 204 (2017) 73-76.

[34] Z.C. Yao, L.J. Jin, Z. Ahmad, H. Jie, M.W. Chang, J.S. Li, International Journal of Pharmaceutics, 524 (2017) 148-158.

[35] S. Gautam, S. Mahaveer, Int. J. Pharm. Studies. Res., 2 (2011) 77-84.

[36] R. Shi, Y. Bin, X. Jian, Polym. Bull., 75 (2017) 1-16.

[37] M. Fadaie, E. Mirzaei, B. Geramizadeh, Z. Asvar, Carbohydr. Polym., (2018).

[38] A.P. Tiwari, M.K. Joshi, J.I. Kim, A.R. Unnithan, J. Lee, C.H. Park, C.S. Kim, J. Colloid Interface Sci., 476 (2016) 29-34.

[39] S.U. Maheshwari, V.K. Samuel, N. Nagiah, Ceram. Int., 40 (2014) 8469-8477.

[40] C. Dumitriu, S.I. Voicu, A. Muhulet, G. Nechifor, S. Popescu, C. Ungureanu, A. Carja, F. Miculescu, R. Trusca, C. Pirvu, Carbohydr. Polym., 181 (2018) 215-223. [41] L.R. Pires, V. Guarino, M.J. Oliveira, C.C. Ribeiro, M.A. Barbosa, L. Ambrosio, A.P. Pêgo, J. Tissue. Eng. Regen. Med., 10 (2016) 154-166.

[42] C. Karavasili, N. Bouropoulos, I. Kontopoulou, A. Smith, V.D.M. Marisa, I.U.R. Rehman, Z. Ahmad, D.G. Fatouros, J. Biomed. Mater. Res. A., 102 (2014) 25832589.

[43] R.R.M.D. Freitas, A.M. Senna, V.R. Botaro, Ind. Crop. Prod., 109 (2017) 452458.

[44] A.O. Abioye, R. Armitage, A.T. Kola-Mustapha, Pharm. Res., 33 (2016) 337-357.

[45] A. Goyanes, H. Chang, D. Sedough, G.B. Hatton, J. Wang, A. Buanz, S.

Gaisford, A.W. Basit, Int. J. Pharm., 496 (2015) 414-420.

[46] T. Tagami, K. Fukushige, E. Ogawa, N. Hayashi, T. Ozeki, Biol. Pharm. Bull., 40 (2017) 357.

[47] S.J. Hwang, G.J. Rhee, K.M. Lee, K.H. Oh, C.K. Kim, Int. J. Pharm., 116 (1995) 125-128.

[48] A. Nabi, S. Tasneem, C.G. Jesudason, V.S. Lee, S.B.M. Zain, J. Mol. Liq., 256 (2018).

[49] S.A. Khaled, J.C. Burley, M.R. Alexander, J. Yang, C.J. Roberts, Int. J. Pharm., 494 (2015) 643-650.

[50] N.A. Peppas, J.J. Sahlin, Int. J. Pharm., 57 (1989) 169-172.

[51] B. Zhang, J. He, X. Li, F. Xu, D. Li, Nanoscale, 8 (2016) 15376.

[52] Y. Gao, M.W. Chang, Z. Ahmad, J.S. Li, Rsc. Adv., 6 (2016) 88157-88167.

[53] M. Arruebo, R. Fernández-Pacheco, M.R. Ibarra, J. Santamaría, Nano Today, 2 (2007) 22-32.

[54] C. Zhang, Y. Li, Y. Hu, Y. Peng, Z. Ahmad, J. Li, M. Chang, ACS applied materials \& interfaces, 11 (2019) 7823-7835.

[55] M.N. Nosar, M. Salehi, S. Ghorbani, S.P. Beiranvand, A. Goodarzi, M. Azami, Cellulose, 23 (2016) 3239-3248.

[56] Z.P. Rad, J. Mokhtari, M. Abbasi, Mater. Sci. Eng. C., 93 (2018) 356-366. 
Tables

4 Table 1. Fitting parameters of Para and IBU release from the composite membrane.

Figures

7 Figure 1. (a) The schematic of the 3D EHD printing set-up. (b) Image of stable printing

8 cone. (c) The design of the composite membrane, consisting of two drug loaded parts 9 (CA-IBU and CA-Para) and a central component ( $\mathrm{PCL}-\mathrm{Fe}_{3} \mathrm{O}_{4} \mathrm{NPs}$ ).

Figure 2. Photographs of printed composite membranes with different layers of folding part (P5, P10 and P20) with a scale of $10 \mathrm{~mm}$.

Figure 3. (a) Stress-strain curves of different printed composite membranes (P5, P10 and P20), the inserts show the images of P5, P10 and P20 after tension tests with a scale of $10 \mathrm{~mm}$. (b) Maximum stress and Maximum strain of P5, P10 and P20.

Figure 4. The unfolding study of different composite membranes (P5, P10 and P20): (a) unfolding angles and images of P5, P10 and P20 after 15 minutes' standing; (b) unfolding angles and images of P5, P10 and P20 after 15 minutes' oscillation.

Figure 5. SEM images of the composite membrane and the diameter distribution graphs: (a) Central component with 10 layers; (b) CA-Para part with 10 layers; (c) CA20 IBU part with 10 layers. (a'), (b') and (c') are magnified images of (a), (b) and (c), 21 respectively.

22 Figure 6. FTIR spectra of pure PCL, CA, Para, IBU and the composite membrane.

23 Figure 7. (a) DSC curves of pure PCL, CA, Para, IBU and the composite membrane. 24 (b) XRD patterns of pure PCL, CA, Para, IBU and the composite membrane.

25 Figure 8. Drug release profiles of Para and IBU from the composite membrane in the 26 simulated gastrointestinal tract.

27 Figure 9. SEM images of the composite membrane after $8 \mathrm{~h}$ drug release: (a) central 
1 component; (b) CA-Para part; (c) CA-IBU part. (a'), (b') and (c') are magnified images

2 of (a), (b) and (c), respectively.

3 Figure 10. (a) Magnetic curves of the composite membrane. (b) Composite membranes 4 response to an externally applied magnetic source.

5 Figure 11. Fluorescent micrographs of L929 cells with the composite membrane: (a) 6 CA-IBU part; (b) CA-Para part; (c) Central component. (a'), (b') and (c') are magnified 7 images of (a), (b) and (c), respectively. Inserts in (a'), (b') and (c') are bright field 8 images.

9

10

11

12

13

14

15

16

17

18

19

20

21

22

23

24

25 


\section{Tables}

4

$5 \quad$ Table 1

\begin{tabular}{llllll}
\hline Drug & $\begin{array}{l}\text { Zero order } \\
\left(\mathbf{R}^{2}\right)\end{array}$ & $\begin{array}{l}\text { First order } \\
\left(\mathbf{R}^{2}\right)\end{array}$ & Higuchi $\left(\mathbf{R}^{2}\right)$ & $\begin{array}{l}\text { Korsmeyer- } \\
\text { Peppas }\left(\mathbf{R}^{2}\right)\end{array}$ & n value \\
\hline Para & 0.4407 & 0.9759 & 0.7621 & - & - \\
IBU & 0.9195 & 0.9701 & 0.9928 & 0.9885 & 0.5 \\
\hline
\end{tabular}

6

7

8

9

10

11

12

13

14

15

16

17

18

19

20 
3

$4 \quad$ Figures

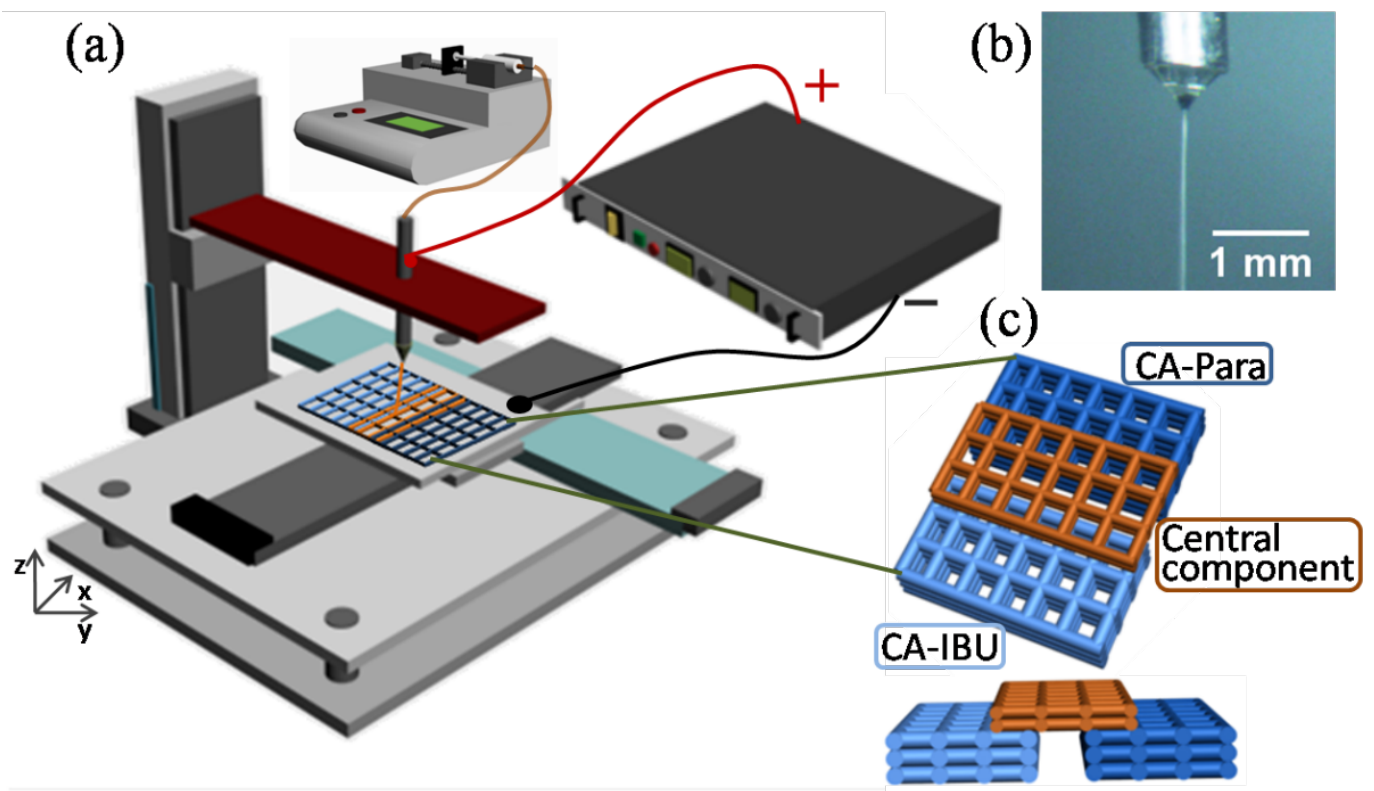

5

6

Figure 1

7

8

9

10

11

12

13

14

15

16 
3

P5
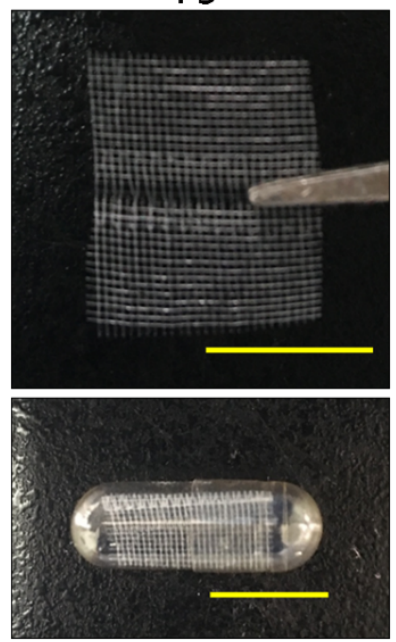

5

6

7

8

9

10

11

12

13

14

15

16

17

(

(

8

(9)

1

2

3

5

7
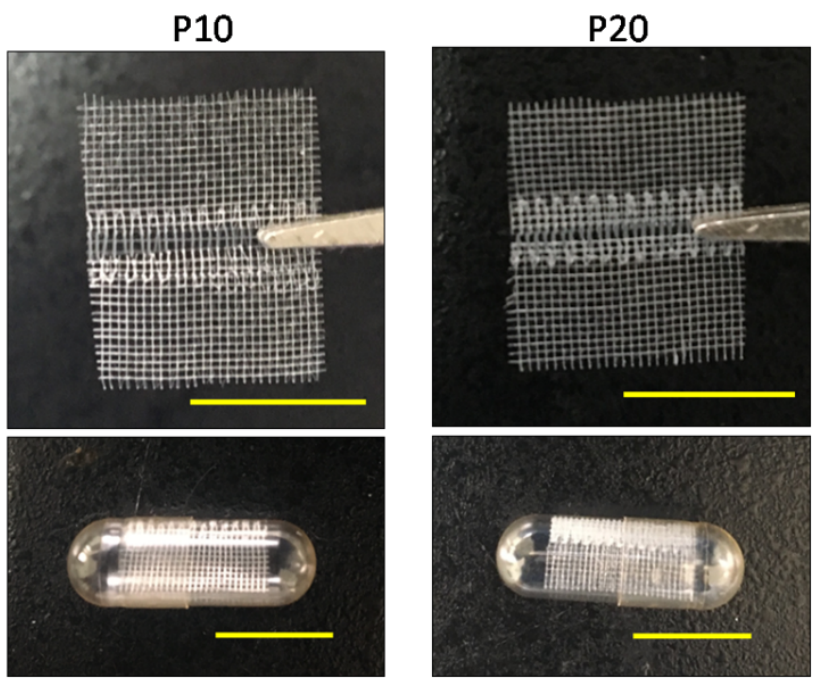

Figure 2 

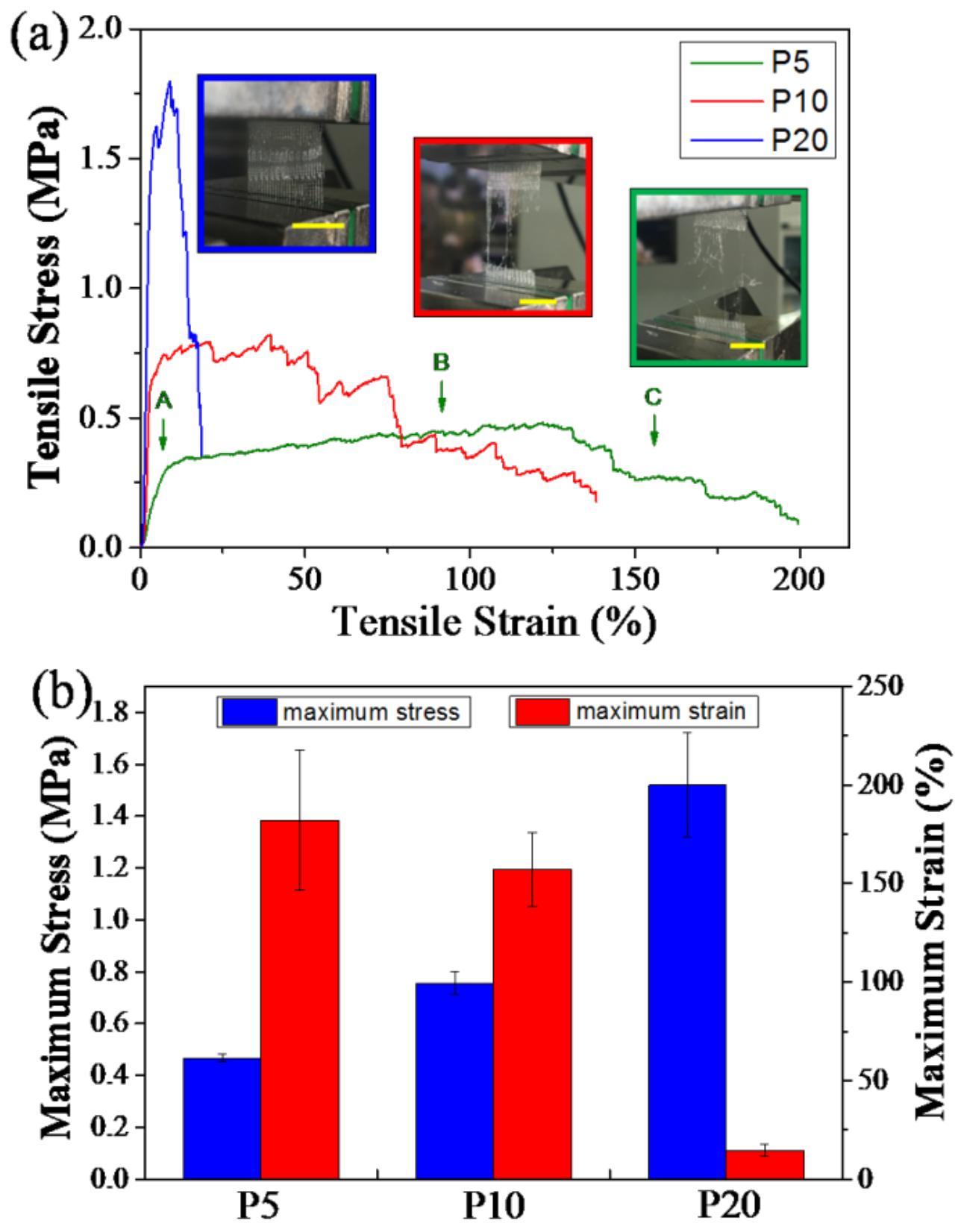

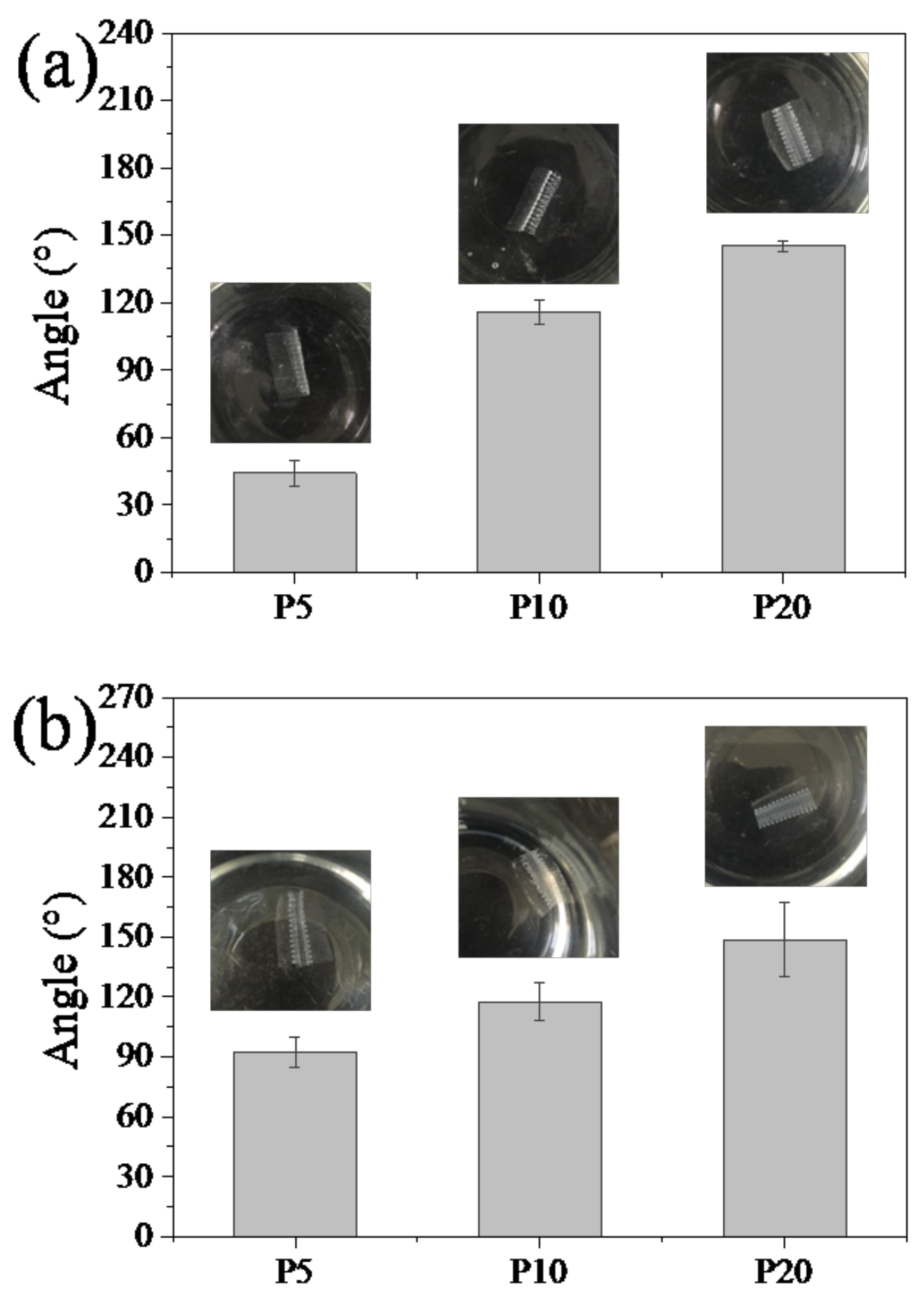

Figure 4

4

5

6 
3

4

5
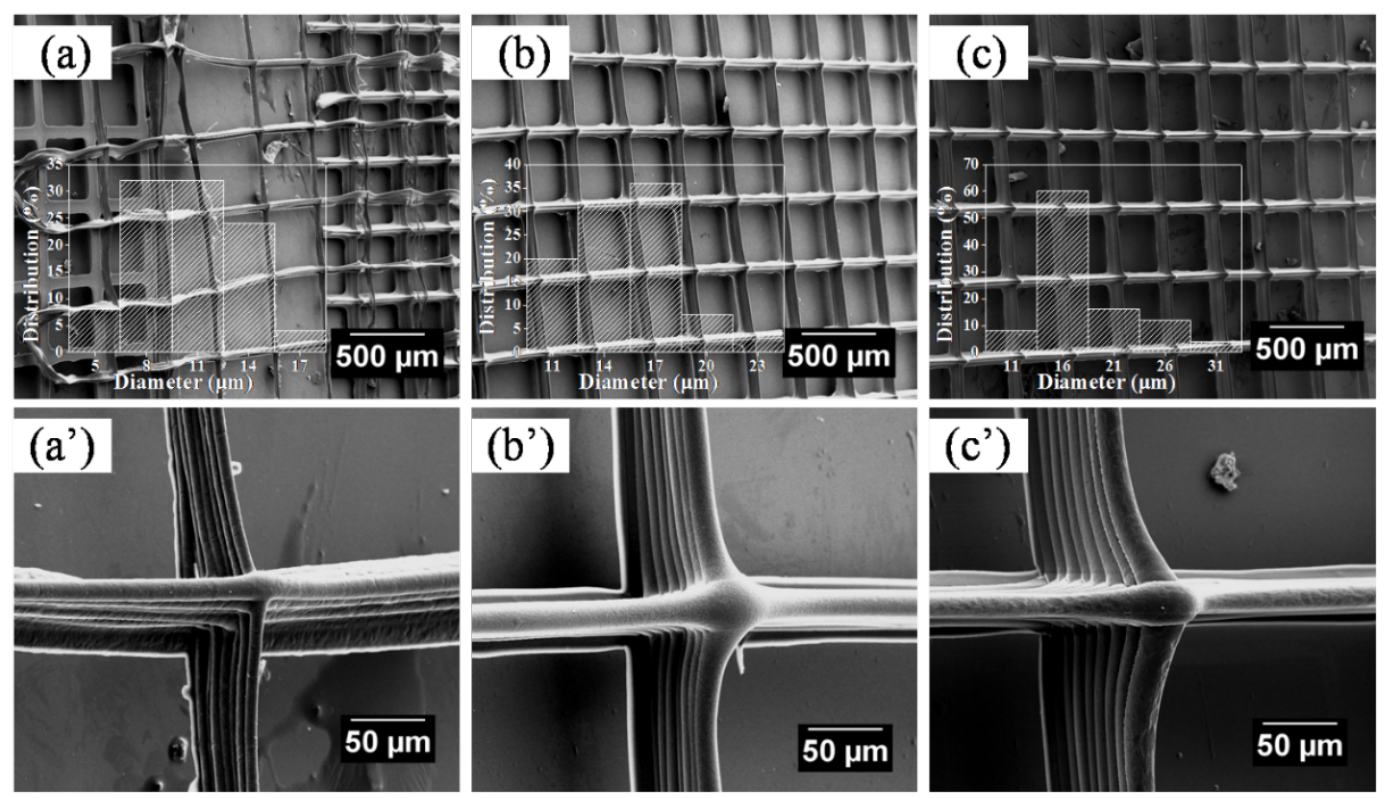

6

Figure 5

7

8

9

10

11

12

13

14

15

16 


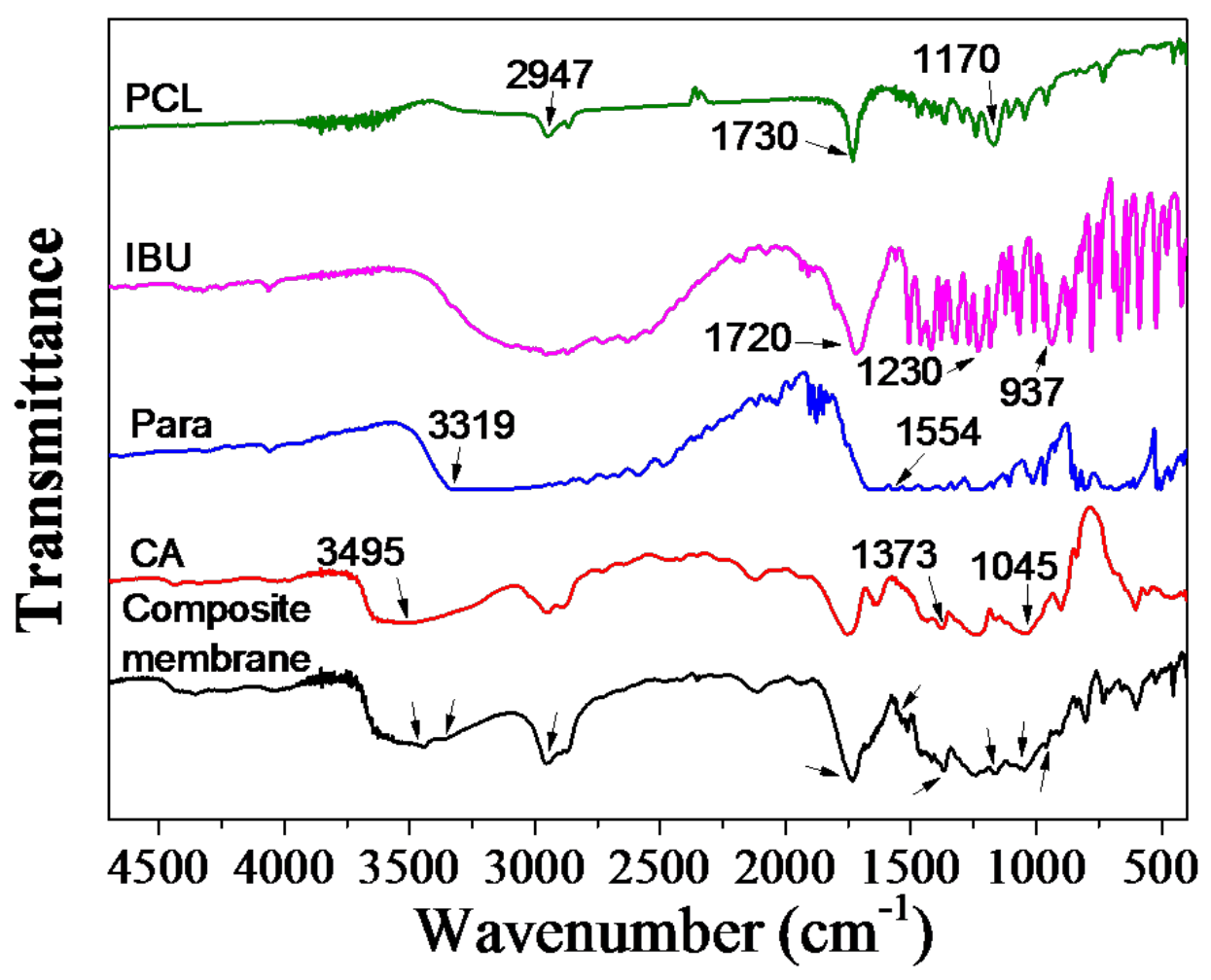

Figure 6

6

7

8

9 

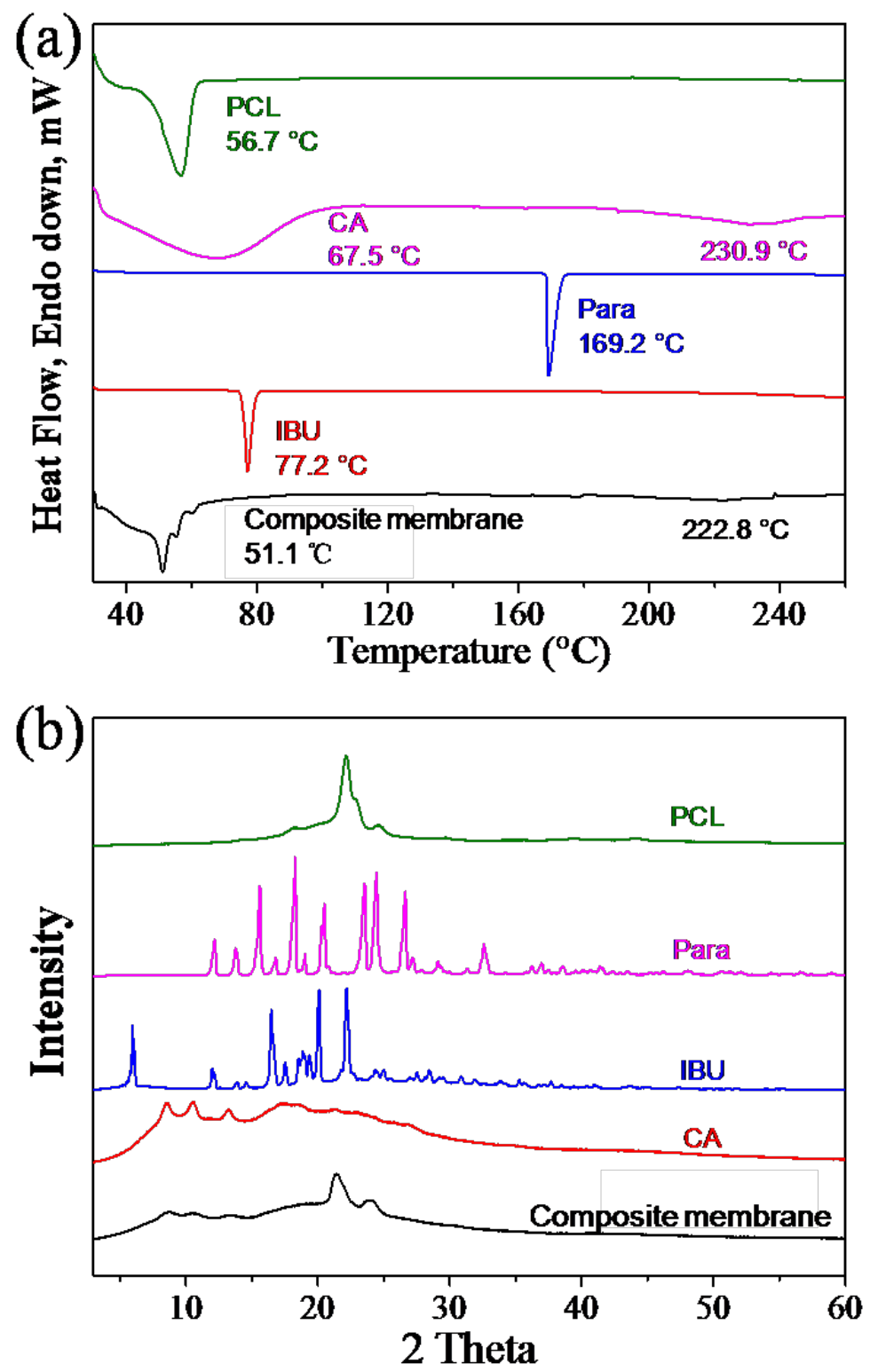

2

Figure 7

3

4

5

6

7

8

9 


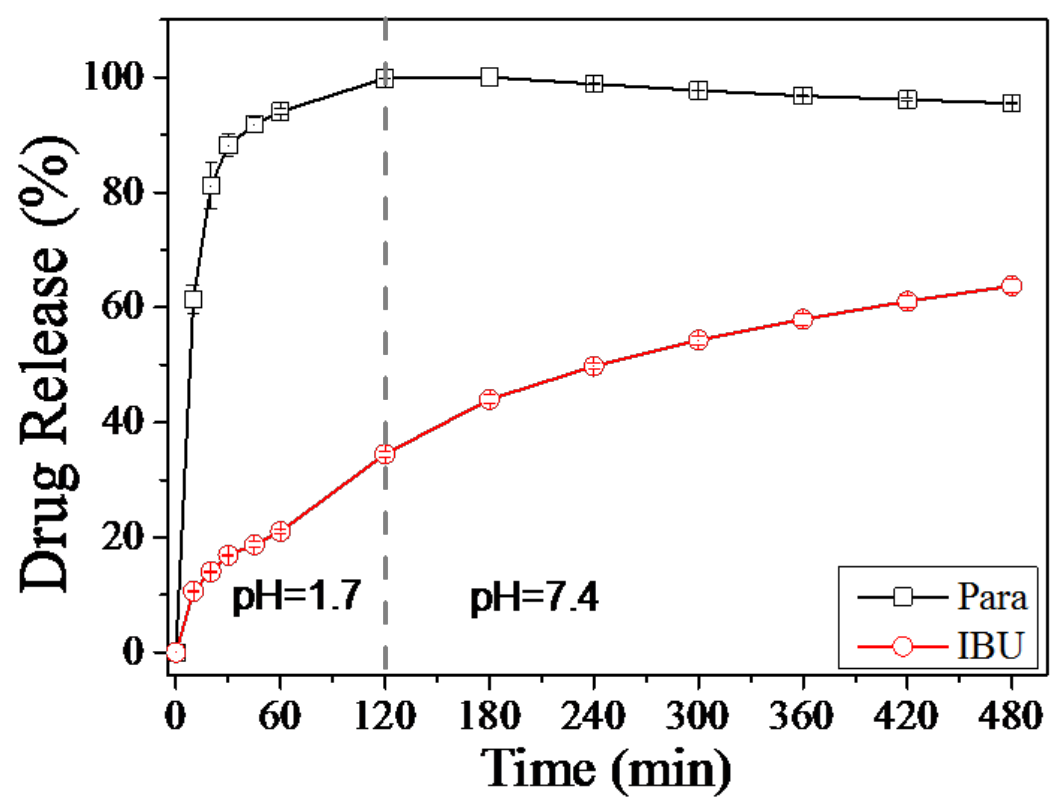

4

Figure 8

5

6

7

8

9

10

11

12

13

14

15

16 
3
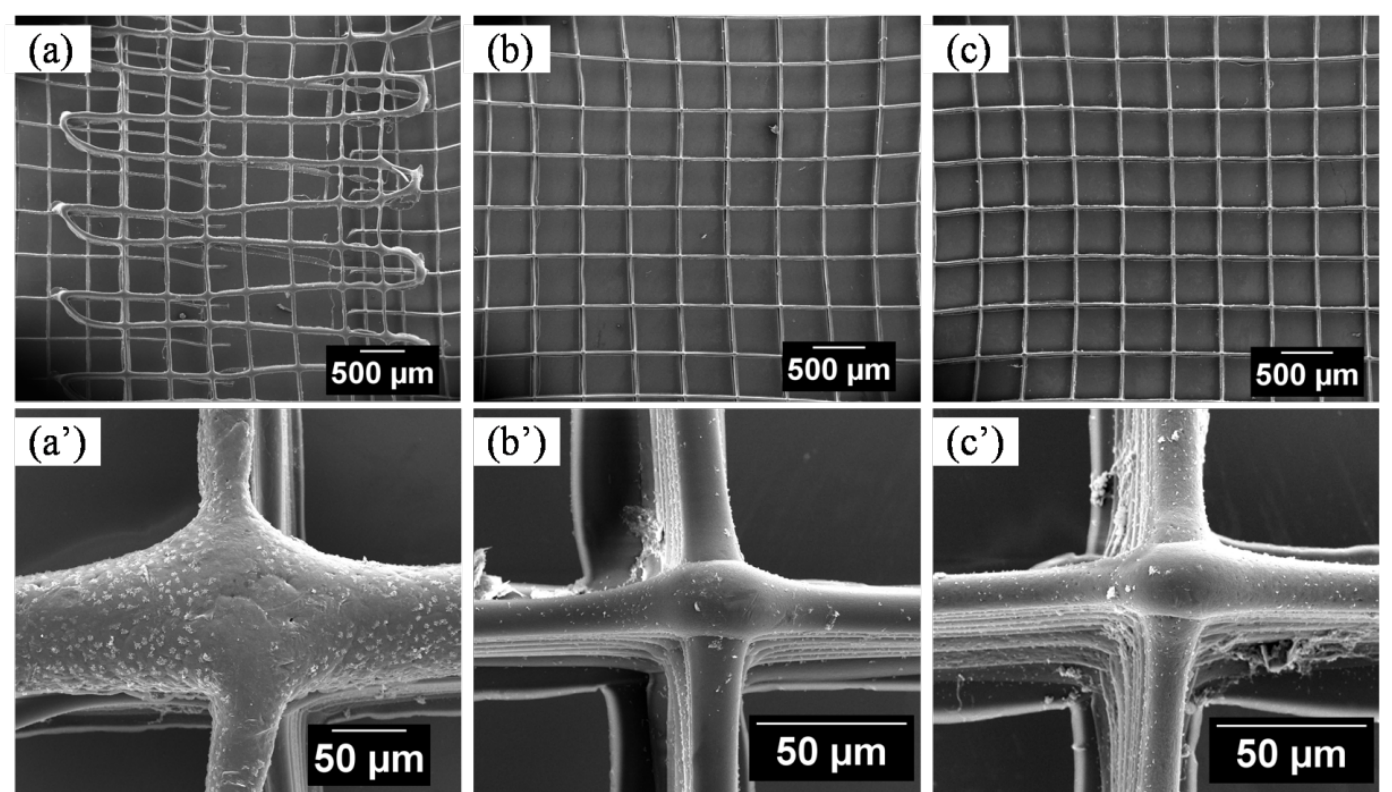

5

Figure 9

6

7

8

9

10

11

12

13

14

15

16 

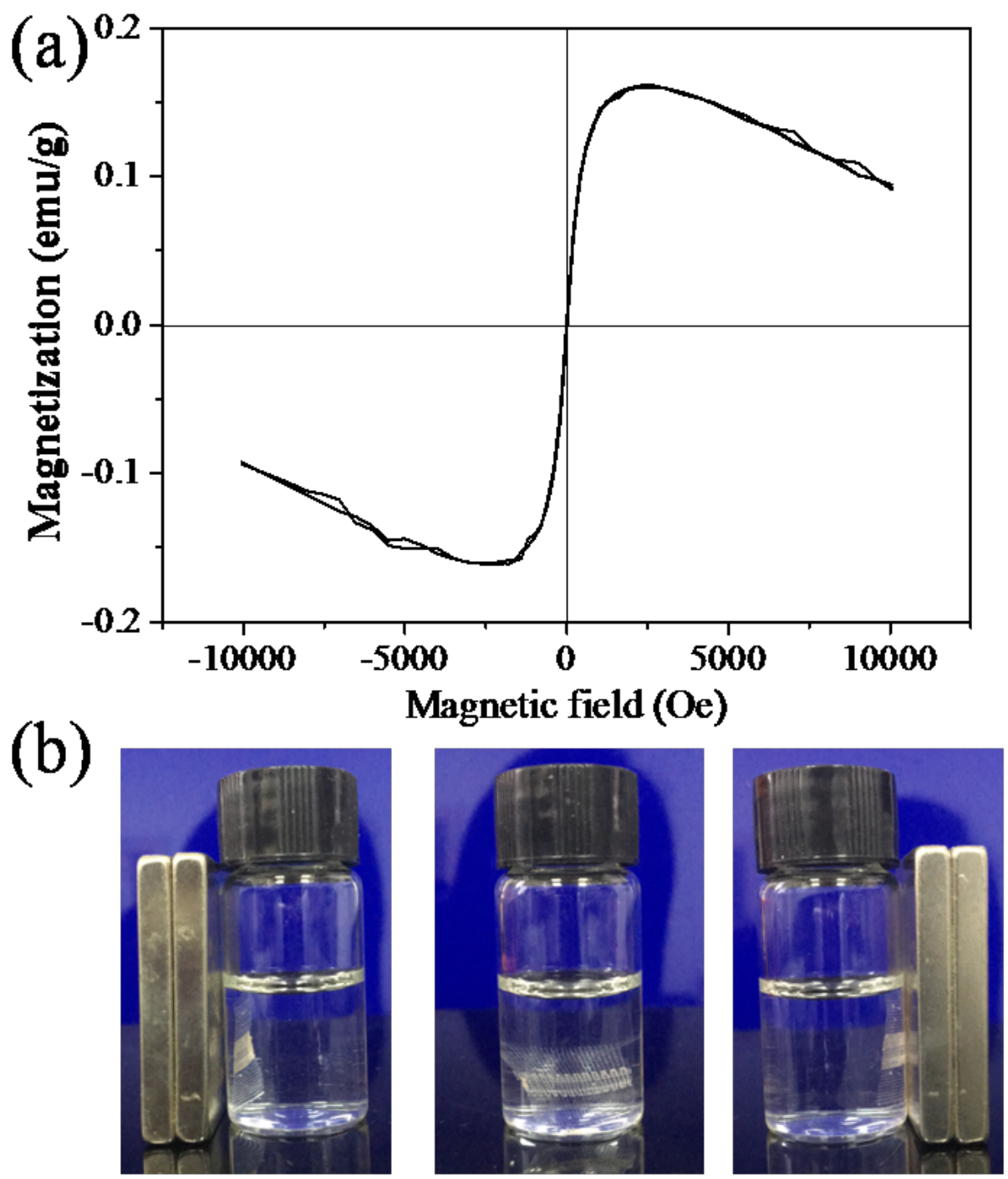

5

Figure 10

6

7

8

9 


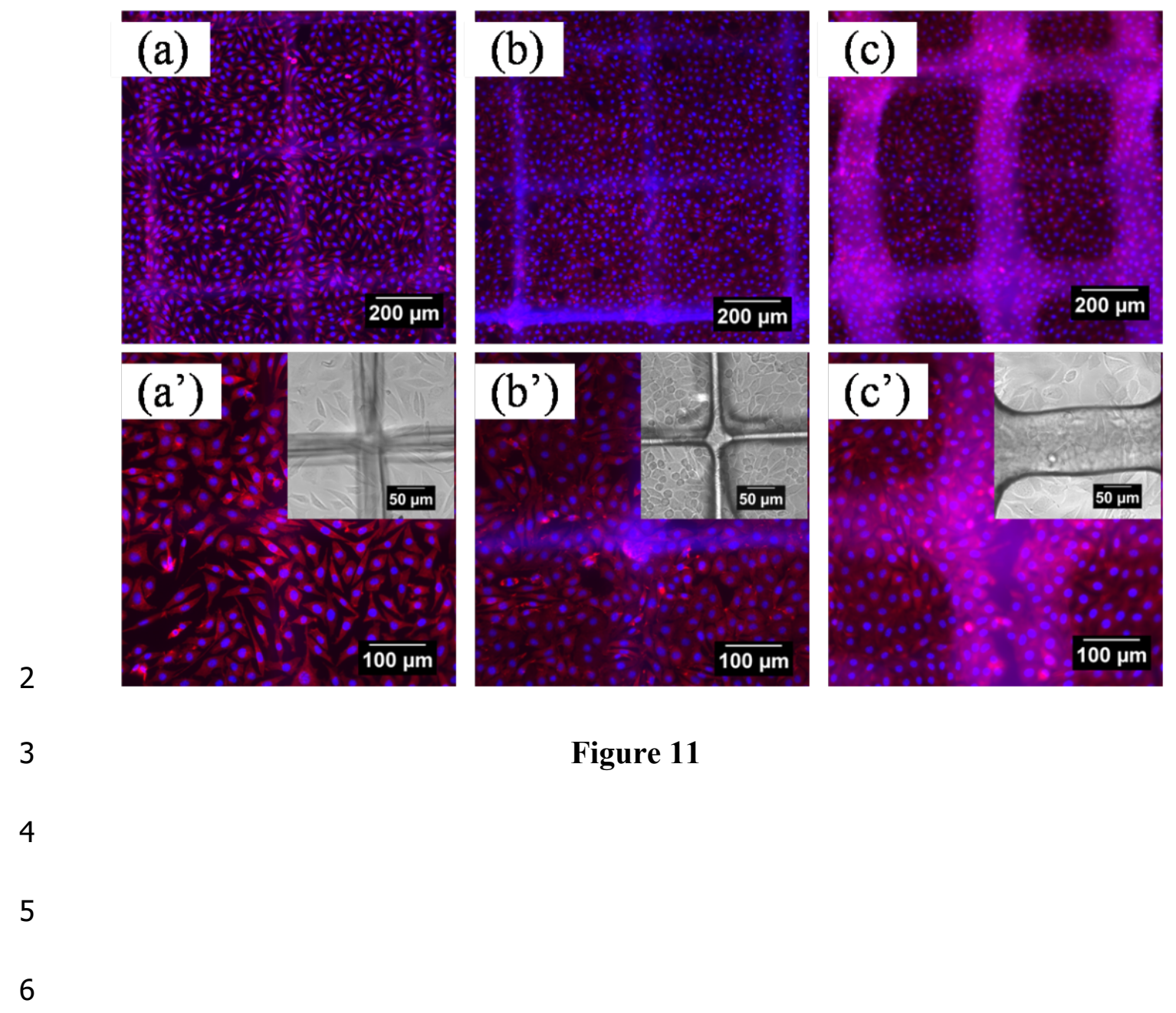

